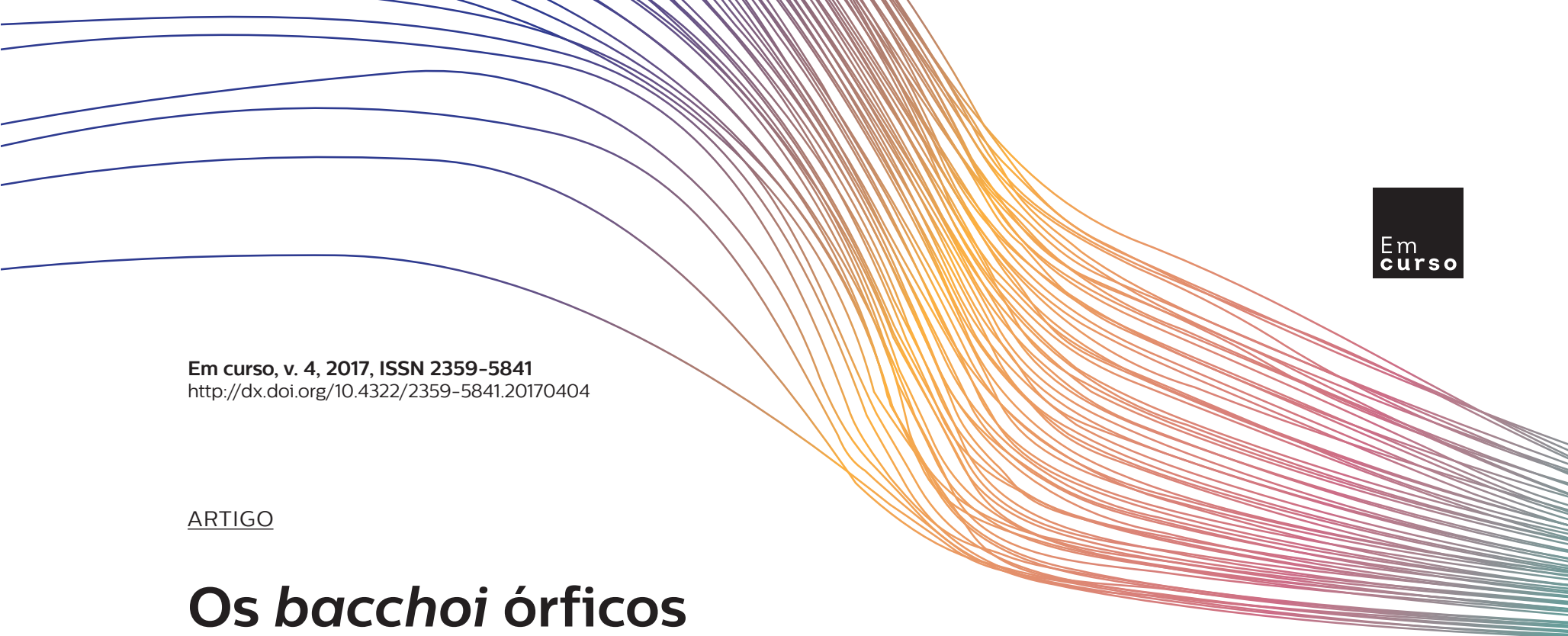

\title{
Os bacchoi órficos
}

\section{The orphic bacchoi}

\section{Giovanna Braz}

Graduação em andamento em Filosofia (2015). Universidade Federal de São Carlos - UFSCar Centro de Educação e Ciências Humanas, Departamento de Filosofia e Metodologia das Ciências, São Carlos, SP - Brasil.

Resumo: Transposição é o nome dado pelos estudiosos à adaptação que Platão faz de doutrinas que não são suas ao seu próprio pensamento, interferindo tanto na interpretação dos elementos que utiliza como também os modificando. No Fédon, a transposição do êxtase (baccheia) órfico à noção platônica de filosofia marca, em 69c-d, a identidade entre a figura dos verdadeiros filósofos (alethos philosophoi) e dos bacantes (bacchoi) órficos: "como dizem os entendidos nos mistérios, 'muitos são os portadores de tirso, mas poucos os bacchoi'. Ora, estes últimos, quer-me parecer que não são outros senão os que se consagraram, no verdadeiro sentido da palavra, à filosofia". Tendo em vista uma futura compreensão dessa transposição, este artigo tem como objetivo apresentar o Orfismo, dando destaque às noções de bacchos e baccheia, marcando sua distinção entre órficos e dionisíacos.

Palavras-chave: Platão; Mistérios; Transposição; Bacchos; Baccheia.

Abstract: Transposition is the name given by the schollars to the adaptation made by Plato to douctrines that weren't his own, to his own thoughts, interfering both in the interpretation of elements he uses as well as modifying them. On the Phaedo, the transposition of the orphic ecstasy (baccheia) to the platonic notion of philosophy marks, on $69 \mathrm{c}-\mathrm{d}$, the identity between the figure of the true philosophers (alethos philosophoi) and of the orphic bacchants (bacchoi): "For 'many', as they say in the mysteries, 'are the thyrsus-bearers, but few are the bacchoi' - meaning, as I interpret the words, those who have been true philosophers". Given the understanding of this transposition, this article aims to present Orphism, highlighting the notions of bacchos and baccheia and it's distintcion between orphic and dionysian.

Keywords: Plato; Mysteries; Transposition; Bacchos; Baccheia. 


\title{
Introdução
}

Não são incomuns na obra platônica os momentos em que ocorrem apropriações de doutrinas alheias, uma espécie de adaptação que Platão faz de doutrinas que não são suas ao seu próprio pensamento, interferindo tanto na interpretação dos elementos que utiliza como também os modificando a fim de assimilá-los. A este procedimento os estudiosos chamaram de transposição ${ }^{1}$ :

\begin{abstract}
"Trata-se de uma maneira pela qual o filósofo cita ou alude a passagens de outros autores, geralmente prestigiosos, como apoio às suas próprias teses, e opera sobre tais citações modificações mais ou menos sutis, seja a propósito das palavras que usa, seja pelo contexto no qual as insere, de modo que transforma também o seu significado ou a sua intenção, especialmente para fazer com que se acomodem às suas próprias ideias, pondo em relevo o que têm em comum e ocultando ou transformando o que as diferencia." (Bernabé, 2011, pp. 367-8).
\end{abstract}

No diálogo Fédon, cujo drama filosófico se passa durante o último dia de vida de Sócrates, Platão transpõe os requisitos órficos para a salvação da alma (psyche) após a morte à sua noção de filosofia: a iniciação (myesis), a purificação (katharsis), o cumprimento dos ritos (telesis) ${ }^{2}$ e o êxtase báquico (baccheia) passam a ser atividades próprias da vida filosófica, não mais dos círculos religiosos. Diante disso, este artigo ${ }^{3}$ consiste num primeiro passo em direção à compreensão da transposição da baccheia órfica, que resulta na identificação do verdadeiro filósofo (alethe philosophos) à figura do bacchos órfico (69c-d), tendo como objetivo, portanto, uma apresentação geral do Orfismo, dando destaque às noções de bacchos e baccheia tal como sua distinção entre órficos e dionisíacos.

\section{As religiões de mistérios}

À margem da religião oficial na Grécia antiga havia as chamadas religiões de mistérios, compostas pelos mistérios de Elêusis, os dionisíacos e os órficos. Deméter e Perséfone eram as deusas cultuadas nos mistérios eleusinos, enquanto Dioniso era a principal divindade para o Dionisismo e para o Orfismo. A palavra mistério (mysterion) vem do grego myein, cujo significado seria algo próximo de "calar a boca" ou "fechar os olhos", daí essas tradições se caracterizarem por manterem em sigilo as suas práticas, sendo necessário ser um iniciado para ter acesso ao seu conteúdo ${ }^{4}$.

A contraposição mais evidente e fundamental entre a religião cívica e as tradições mistéricas está no conceito de psyche (alma). Na tradição homérica, a alma era tida como uma sombra que se esvai do corpo para o hades, que não expressa uma parte essencial do homem, existente apenas no momento da morte e desaparecendo após

\footnotetext{
${ }^{1}$ Conceito criado por August Diès (1927) na obra Autour de Platon: essais de critique et d'histoire, vol. 2.

2 Não há tradução satisfatória para o termo telete. A tradução usual, "iniciação", é insatisfatória dado que o termo não se refere apenas a ritos de iniciação, mas a ritos diversos que eram realizados em vários momentos ao longo da vida dos iniciados, sempre relacionados ao âmbito dos Mistérios. As teletai eram destinadas a livrar os iniciados dos pecados e assegurar uma vida melhor neste mundo e no além. cf. Bernabé (2011, pp.37-42).

${ }^{3}$ Texto apresentado no VIII Encontro de Pesquisa na Graduação em Filosofia da UFSCar.

${ }^{4}$ A literatura órfica é composta de diversos exemplos da intenção de ocultar o significado de suas doutrinas. A expressão "Falarei a quem é lícito. Fechadas as portas, profanos", ou mesmo suas variantes, como "Cantarei aos conhecedores. Fechadas as portas, profanos" e "Exortando aos profanos que fechem as portas", eram localizadas já no início dos textos com a finalidade de dissuadir a leitura aos não iniciados e indicar também a necessidade de determinados conhecimentos prévios para decifrá-los. Isso se tornou uma marca dos discursos sagrados (ieroi lógoi) órfico-pitagóricos. Sobre esse tema, conferir BERNABÉ, A. 'La fórmula órfica "cerrad las puertas, profanos". Del profano religioso al profano en la materia'. 'Ilu. Revista de ciencias de las religiones 1, 1996, pp. 13-27. E também BERNABE, A. El silencio entre los órficos. 'Ilu. Revista de Ciencias de las Religiones, XIX, 2007, pp. 53-66.
} 
este. Por outro lado, nas religiões de mistérios a psyche é vista como uma parte imortal do homem, na qual reside toda sua individualidade. É aqui que surge no ocidente uma noção rudimentar de indivíduo. Os mistérios introduzem, sobretudo os mistérios órficos, a noção de uma alma imortal, a preocupação com o seu destino após a morte e sua decorrente sorte no além (hades), derivada de seus modos de vida. Entretanto, vale sublinhar que não havia nestas tradições a preocupação em definir o que é a psyche e quais seus respectivos poderes, investigações que surgirão apenas com os filósofos pré-socráticos.

\section{Os mistérios órficos}

O Orfismo se destaca entre as religiões mistéricas por inovar a religiosidade grega: trata-se de uma tradição fundamentalmente escrita. Possui livros sagrados atribuídos a Orfeu e a Museu, compostos de poemas teogônicos (sobre a genealogia dos deuses), cosmogônicos (narrativas sobre a formação do cosmos, que incluíam um mito de formação da espécie humana) e poemas escatológicos (revelações sobre o Hades e o percurso da alma depois da morte). Estes poemas eram tratados como uma espécie de enigma, segundo o qual somente uma interpretação alegórica deveria revelar seu conteúdo secreto. Temos um exemplo desse método interpretativo nos papiros de Derveni ${ }^{5}$, que apresentam interpretações alegóricas das Rapsódias Órficas contaminadas pelas cosmogonias de filósofos como Anaximandro e Heráclito (GAZZINELLI, 2007, p. 13). Além disso, esses papiros mostram que a religião órfica tinha um bom diálogo com a filosofia. Para Vernant (2006, p. 82), é a forma "doutrinária" de tradição fundamentalmente escrita que opõe o Orfismo aos outros mistérios, ao mesmo tempo que o aproxima da filosofia.

Os princípios religiosos órficos estão fundamentados numa reinterpretação de um mito dionisíaco segundo o qual, no início dos tempos, os Titãs matam Dioniso por inveja, despedaçam-no, cozinham-no e o devoram. Zeus, irritado com tal feito, fulmina os Titãs com um raio e de suas cinzas nascem os homens, formados por um componente negativo, proveniente dos Titãs, o corpo, e por um componente divino, proveniente de Dioniso, a alma. O ser humano é, então, um misto de corpo e alma, de mortal e imortal, e devido à culpa titânica do sacrifício, deve purgar seu crime num corpo que é como um túmulo - o conhecido mote órfico soma-sema: o corpo (soma) é o túmulo (sema) da alma. Por sua vez, a natureza dual do ser humano e sua imortalidade fundamentam a transmigração da alma e a necessidade de escapar desse ciclo de reencarnações, também chamado de metempsicose ${ }^{6}$. O cumprimento dos ritos (telesis ${ }^{7}$ ), a iniciação (myesis), a purificação (katharsis) e demais práticas ascéticas teriam a função de acelerar o processo libertação do clico transmigratório ${ }^{8}$, proporcionando ao purificado e liberto a comunhão com os deuses no além.

\footnotetext{
${ }^{5}$ Papiro encontrado em 1962 no nordeste da Grécia, num sítio arqueológico composto por seis tumbas perto da Tessalônica. A datação do papiro é controversa, mas as tumbas datam do fim do século IV a.c., tratando-se do mais antigo papiro grego e do mais antigo texto literário conhecido. Sobre o Papiro de Derveni, cf. BERNABÉ, A. The Commentary of the Derveni Papirus. The Last of Presocratic Cosmogonies. Littera Antíqua, 7, p. 4-31, 2013. E também BERNABÉ, A. The Derveni Theogony: Many questions and some answers. HSCPh 103, 99-133. Gábor Betegh, 2004.

${ }^{6}$ Alguns estudiosos, como Giovanni Reale, preferem utilizar o termo metensomatose, pois metempsicose indicaria mudança de alma e não de corpos, enquanto metensomatose indicaria mudança de corpos e não de alma. Vide REALE, G. História da Filosofia Antiga. V: Léxico, Índices e Bibliografia. Trad. Henrique Cláudio de Lima Vaz e Marcelo Perine. São Paulo: Loyola, 2005, verbete "Metempsicose").

${ }^{7}$ Cf. nota 2.

${ }^{8}$ Sobre o tema da transmigração, cf. BERNABÉ, A. La transmigración entre los órficos. In BERNABÉ; KAHLE, MADAYO Y SANTAMARÍA, MARCO ANTONIO (eds.), Reencarnación. La transmigración de las almas entre Oriente y Occidente. Madrid, Abada, 2011.
} 
Uma breve contraposição entre o orfismo e o dionisismo pode nos oferecer detalhes preciosos a respeito da nova concepção de homem e seu relacionamento com o mundo inaugurado pelo orfismo na Grécia antiga. Esses aspectos são fundamentais para a compreensão das figuras do bacchos e da baccheia em ambas as tradições. Como bacchos - e, portanto, baccheia - é uma figura tipicamente dionisíaca, isto é, presente, portanto, tanto no Orfismo quanto no Dionisismo, faz-se necessária essa distinção, já que é "versão" órfica a de que Platão se apropria. Vejamos.

\section{Orfismo \& Dionisismo}

Apesar de serem ambas religiões dionisíacas, isto é, fundarem-se sob a figura de Dioniso, o Orfismo e Dionisismo mostram-se na prática como duas tradições opostas, dois extremos sobre a relação com o divino e o terreno. A questão do sacrifício torna essa oposição clara:

No dionisismo, o ritual consiste em matar um animal, estraçalhar-lhe e comer-lhe a carne crua. $\mathrm{O}$ fiel que se alimentou com a carne comunica-se com a divindade. $\mathrm{O}$ orfismo prega uma prática radicalmente oposta. Nele a comunicação com o deus é desnecessária, porque o homem carrega em si uma parte divina, ele é o próprio Baco. (...) Essa diferença no significado da relação do homem com a divindade permanece presente e justifica a prática de ambos os movimentos. (OLIVEIRA, 2004, p.12).

Assim, vemos que para o Dionisismo o contato com a divindade se dá através do diasparágmos, isto é, um ritual de devoração crua de um animal acuado e despedaçado vivo; já o orfismo prega uma prática radicalmente oposta, sendo essa comunicação desnecessária, pois o homem carrega em si mesmo uma parte divina: ele é, de certo modo, um pedaço do próprio deus. Além disso, o Orfismo nega todo e qualquer tipo de sacrifício que envolva seres vivos ${ }^{9}$, pregando a prática severa do vegetarianismo, pois "a abstenção de carne é a recusa ao sacrifício cruento, assimilado ao homicídio contra um próximo" (VERNANT, 2006, pg. 68). No Orfismo, o divino é elemento característico do próprio homem, e o acesso a ele se dá por meio de uma ascese pessoal, uma "via sagrada" percorrida somente pelos iniciados.

\section{Bacchos e baccheia}

A contraposição acima nos fornece elementos essenciais sobre a figura dos bacchoi e da baccheia órficos e dionisíacos. Especificamente, temos que o êxtase (baccheia) no Dionisismo está relacionado ao sacrifício sanguinário no qual os bacchoi realizam o despedaçamento (diasparágmos) de um animal vivo a fim de comunicar-se com o divino. Baccheýn, o verbo correspondente, tem significado de "entrar em êxtase" ou também "estar louco" ou "parecer louco", e bacchos, então, é o substantivo que designa a pessoa que entra nesse transe ou delírio temporário.

Por sua vez, os significados de bacchos e baccheia na literatura órfica diferem imensuravelmente do dionisíaco. Comecemos por um fragmento (Fr. 474) da Lâmina de Ouro de Hipônio (400 a.C.), que apresenta uma personagem que se dirige ao morto para descrever os lugares que irá percorrer em seu caminho ao Além e dar recomendações sobre o que se deve e o que não se deve fazer para obter um destino melhor do que o comum dos defuntos. Esse fragmento é importante, pois nos revela,

${ }^{9}$ Isto é, seres que possuem carne e sangue. 
antes de tudo, a existência de dois tipos de iniciados dentro dos mistérios órficos, os mistai $^{10}$ e os bacchoi. Diz o poema:

Isto é obra da Memória (Mnemosyne). Quando estiver em transe de viajar [morrer] ${ }^{11}$

para a bem construída morada de Hades, há, à direita, uma fonte

e próximo a ela, ereto, um cipreste branco.

Ali, ao baixar, as almas dos mortos se refrescam.

Dessa fonte não te achegues perto nem um pouco!

Porém, mais adiante encontrarás, da lagoa de Mnemosyne,

água que flui fresca. E em sua margem, guardiões.

Eles te perguntarão, com sagaz discernimento,

por quê investigas as trevas do Hades sombrio.

Diga: "Sou filho da Terra e de Céu estrelado;

de sede estou seco e morro. Dá-me, pois,

de beber da água fresca da lagoa de Mnemosyne".

E de certo que consultarão com a rainha subterrânea,

e te darão de beber da lagoa de Mnemosyne.

Então, uma vez que tenhas bebido, também tu te irás pela sagrada via

pela qual os demais iniciados (mistai) e bacos (bacchoi) avançam gloriosos. ${ }^{12}$

Mistas e Bacos formam, pois, as categorias de iniciados nos mistérios órficos. E o que os diferencia uns dos outros já é indicado na passagem do Fédon em que Platão identifica os alethos philosophoi aos bacchoi: havia certa gradação entre os iniciados órficos e só uns poucos deles alcançavam uma categoria especial, a de bacchos: "muitos são os portadores de tirso, mas poucos os bacchoi" (69c-d). Evidentemente, "os portadores de tirso" correspondem aos mistai, o comum dos iniciados.

\footnotetext{
10 “O místico é o sujeito da experiência, o mistério, seu objeto, a mística, a reflexão sobre a relação místico-mistério. A derivação etimológica desses termos vem de myein (fechar os lábios ou os olhos), donde, por uma transposição metafórica, "iniciar-se", do qual deriva o complexo vocabular: mýstes, iniciado, mystikós, o que diz respeito à iniciação, tà mystiká, os ritos de iniciação, mistikôs (advérbio), secretamente e, finalmente, mystérion, objeto da iniciação" VAZ, H. C. L. Escritos de Filosofia V: Introdução à Ética Filosófica 2. São Paulo, Loyola, 2000., pg.18, nota 6 .

${ }^{11}$ Aqui "morrer" se constrói como verbo de movimento (thaneithai) porque a morte é vista como um trânsito, como viagem ao outro mundo, e por isso carrega o modo com "para", "morrer para o hades". Cf, BERNABÉ (2012, pg. 315, nota 4$)$.

${ }^{12}$ Tradução de Bernabé (2012, pg. 135).
} 
Dentre os estudiosos, René Turcan (1986), ao analisar uma inscrição de Cumas em que se lê "Não é lícito jazer aqui quem não se converteu em um baco", baseia-se no fato de que na inscrição se usa o particípio perfeito bebaccheimenon, que no grego indica o estado presente resultado de uma ação passada, para concluir que entre os órficos a baccheia não era um estado transitório, tal como no dionisismo, e sim uma condição durável, isto é, um estado permanente. Torna-se bacchos. Alberto Bernabé (2010) nota, endossando a interpretação de Turcan, que a favor dele está o fato de que também Platão utiliza as mesmas formas de particípio perfeito, no Fédon (69c), para se referir aos iniciados: memyemenos (iniciados), kekatharmenos (purificados), tetelesmenos (cumpridos os ritos) e bebaccheymenos (extáticos). Jiménez San Cristóbal (2009) também se debruçou sobre a questão do bacchos órfico. A estudiosa chega à conclusão, na mesma esteira dos estudiosos supracitados, de que o êxtase órfico se distancia da atividade violenta e transitória do bacchos dionisíaco, cuja baccheia se dava através do diasparágmos cruel, do sacrifício sangrento. Os órficos, ao contrário, entendiam o êxtase báquico como um estado permanente de bem-aventurança alcançado através de uma ascese pessoal. Àqueles poucos capazes de alcançar tal estado de pureza chamavam-nos de bacchoi.

\section{Considerações finais}

Retomando em linhas gerais, para finalizar, vimos que a figura do bacchos está presente tanto nos mistérios órficos quanto nos mistérios dionisíacos. Do contraste entre o modo como ambas as tradições se posicionam com relação à questão do sacrifício, pudemos observar que o êxtase báquico (baccheia) dos bacchoi dionisíacos está baseado numa atividade violenta e transitória, correspondente a um estado de contato temporário com o divino. Com relação aos órficos, vimos por intermédio do poema da lâmina de ouro de Hipônio a existência de duas categorias entre seus iniciados, os mistai e os bacchoi. Estes últimos correspondem a um tipo especial de iniciados, caracterizado pelo alcance a um estado permanente de baccheia, um estado imutável de bem-aventurança resultado de uma árdua ascese pessoal. Estes são, pois, os bacchoi órficos, os quais Platão identifica, no Fédon, aos verdadeiros filósofos (alethos philosophoi). Assim, dado esse primeiro momento de caracterização da figura do bacchos órfico, podemos seguir nossa pesquisa em busca da compreensão de sua transposição ao âmbito filosófico.

Correspondência: Giovanna Braz. Universidade Federal de São Carlos - UFSCar. Centro de Educação e Ciências Humanas. Departamento de Filosofia e Metodologia das Ciências. Rodovia Washington Luís. km 235. Monjolinho. São Carlos - SP - Brasil. CEP: 13565-905. E-mail: gi.braz@outlook.com

Apoio financeiro: Nenhum

Conflito de interesses: Nenhum

Todos os autores leram e aprovam a versão final submetida à revista Em curso. 


\section{Bibliografia}

BERNABÉ, Alberto. Platão e o Orfismo. Diálogos entre religião e filosofia. Trad. Dennys Garcia Xavier. São Paulo: Annablume Clássica, 2011.

São Paulo: Paulus, 2012.

Hieros logos: Poesia órfica sobre os deuses, a alma e o além. Tradução de Rachel Gazolla.

GAZZINELLI, Gabriela Guimarães (org. e trad.). Fragmentos Órficos. Belo Horizonte: Editora UFMG, 2007.

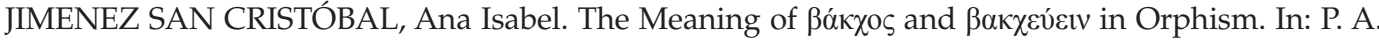
JOHNSTON and G. CASADIO (eds.), Mystic Cults in Magna Graecia. Austin: University of Texas Press, 2009, pp. 46-60.

OLIVEIRA, Anselmo Carvalho de. Orfismo, uma nova dimensão do homem grego. Ágora Filosófica, ano 4, n. 2, jul./dez. 2004, pp. 7-19.

PLATÃO. Fédon. Intr., trad. e notas de Maria Teresa Schiappa de Azevedo. Brasília: Editora UNB, 2001.

TURCAN, René. Bacchoi ou bacchants? De la dissidence des vivants à la ségrégation des morts. In: $A A . V V$., L'association dionysiaque dans les sociétés anciennes. Roma: École Française de Rome, 1986, pp. 227-246.

VERNANT, J.P. Mito e religião na Grécia Antiga. São Paulo: Martins Fontes, 2006.

Recebido em: 31/Mar/2017 - Aceito em: 25/Out/2017 